\title{
Research on Horqin Mongolian Traditional Sports Culture
}

\author{
Zhang Hong \\ College of Physical Educaition, Baicheng Normal University, Baicheng, China \\ zhdcrmail@163.com
}

Keywords: Horqin, Mongolian Traditional Sports Culture, Research

\begin{abstract}
Horqin is one of the Mongolian tribes in history, and is also the birthplace of the famous Mongolian regional culture, that is, Horqin culture. In recent years, people attach great importance to the study of Horqin Mongolian traditional sports culture. This paper will focus on the research of Horqin Mongolian traditional sports culture, and hope that through this analysis, the Horqin Mongolian traditional sports culture can be carried forward to a large extent.
\end{abstract}

\section{Introduction}

As we all know, the development of culture must be based on economic development. In recent years, China has attached great importance to the study of minority culture, at the same time, it also issued corresponding policies, and invested a lot of funds to carry out national cultural activities, whose purpose is to let the minority culture continue to develop. Mongolian sports culture has a long history. It is very necessary to study Mongolian traditional sports culture. This paper will aim at this and carry on the related discussion.

\section{The Evolution Process of Horqin Mongolian Traditional Sports Culture}

The Chinese nation has a history of five thousand years, it can be said that China has a long cultural heritage. There are 56 ethnic groups in China, 55 of which are ethnic minorities, which, to some extent, contribute to the richness of Chinese culture. The Mongolian nationality is one of the larger tribes in the minority nationality. If we want to study the minority culture more effectively, we should study the way of life, eating habits and values of the Mongolian nationality. The Mongol, a nation on horseback, is good at riding and controlling horses, that creates a unique sports culture for the Mongols. In the distant ancient times, the Mongols created a lot of colorful sports in order to survive. For example, Mongolian chess, camel racing, Blu and so on. Of course, among these activities, the most grand is the "Nadamu." "Nadamu" means Mongolian game and entertainment. Nadamu is a traditional Mongolian festival with a long history and plays an important role in the life of Mongolian people. Nadamu is held in July and August every year, and its programs include horse racing, wrestling, archery, Mongolian chess and other traditional activities. Today, some places also add athletics, tug of war, basketball and other sports to Nadam. In addition, every spring, Mongolian people will also hold whipping horse bristles, finishing horse tail and other activities, which not only enable people to have healthy physique, but also to cultivate their strong character. Discussing the development of Horqin Mongolian traditional sports culture can let the relevant people understand the rise and fall of Horqin Mongolian traditional sports culture, which is conducive to better carry forward Horqin Mongolian traditional culture.

From the 11th to the 13th century, the Mongols depended on nomads for their livelihood, who have long been engaged in gathering, hunting and other activities, so there are archery, Blu and other traditional Mongolian sports and cultural activities. Blu is mainly used to defend the body with a fast, lethal characteristics. Archery is mainly to increase the capture of long-range prey, but also to better protect their own safety. Therefore, the Mongolian people in this period have paid attention to their archery techniques, which paved the way for the later development of Horqin Mongolian traditional sports culture. From collecting, hunting and other life skills into present sports activities, we have to say, Horqin Mongolian traditional sports culture, directly reflects the 
way of life and life wisdom of people at that time [1].

If the life skills of the Mongols from the 11th to the 13th century lay the groundwork for the later development of Horqin Mongolian traditional sports culture, and so, war is the origin of Mongolian traditional sports. There is survival, there will be competition, there will be killing. Life skills can no longer meet the needs of people, at this time, people urgently need a new form to ensure their survival in the war. Thus, wrestling, conforms to the needs of the times produced. Famous wrestlers on the grasslands are known as "Kobo", which shows the Mongolian love of wrestling. Some say wrestlers are smarter, because wrestling itself is not brute force, and wrestling and attacking require precise control by wrestlers. So wrestling, to a certain extent, also represents the wisdom of the Mongolian people. There are records of the 13 th century, wrestling has a preliminary embryonic form. During that period, wrestling was not only used as a game between people, but also as a key bond between tribes. Of course, at the same time, there were also riding and shooting. Riding and shooting is based on the evolution of the archery. Riding and shooting itself is more aggressive, and more flexible and convenient. This time the riding and shooting can be used not only for hunting, but also for combat. Genghis Khan once said: "hunting is the duty of soldiers," you can see the military value of shooting. The victory or defeat of Mongolian tribes often depends on the number of war horses. During the Yuan Dynasty, the war horses won the world and created the largest territory in the history of China. The power of riding and shooting can be seen.

With the improvement of Mongolian culture, sacrificial culture began to rise. Religion also plays an important role in Horqin Mongolian traditional sports culture. The Mongols worshipped the forces of nature in the early days and began worshiping lamas after worshipping their ancestors in the 16th century. The Mongolian worship of natural power stems from the fear of natural power. When the natural forces such as thunder and fire threaten people lives, people will unconsciously fear and gradually develop a sense of worship. The force of nature is untouchable, and people materialize it, and Aobo appears. Offering sacrifices to Aobo was the most popular and lively activity of that period. Yuan Dynasty Hu Bilie admonition, each year must be to sacrifice the famous mountains and rivers. From this, we can see the importance of sacrificial activities. The sacrifice of Aobo has been going on until now, of course, the content of sacrifice is slightly different from that of traditional sports culture. Now Aobo sacrifice, more is to engage in recreational activities [2]. But the long history of Aobo sacrifice doomed Aobo sacrifice itself can not be separated from the traditional sports culture, or Aobo sacrifice is an indispensable part of the traditional sports culture.

In addition to labor, war, sacrifice, the Mongolian people have begun to attach importance to recreational activities. The main entertainment activities of Mongolian people are singing and dancing. Song and dance entertainment itself is not a sports activity, but it has a great influence on the traditional sports culture. After the end of labor and the victory of the war, the Mongolian people expressed their joy by singing and dancing, and the inspiration for the creation of these dances came from imitating the different gestures of different birds and beasts. It can also be seen that dance activities and traditional sports are closely related. In addition, the individual dance, gradually evolved into a group dance. When victory or harvest, the Mongols began to dance to celebrate, expressing inner joy. At this time, the group dance, has been in the Mongolian people life, occupies an important position, which can also fully illustrate the interaction between entertainment and traditional sports. At this time, there is another kind of entertainment, it is Mongolian chess. Mongol is characterized by the creation of hunting chessboards against the background of grasslands and forests. When people play chess, it like a mountain beast fighting. So Mongolian chess symbolizes wisdom and bravery in the hearts of Mongols, as a result, Mongolian chess began to be popular. Mongolian chess was first recorded in the early 17th century, and Mongolian chess has existed in people's daily life for at least hundreds of years. Present chess is the evolution of Mongolian chess.

Horqin is one of the tribes of Mongolia in history. To some extent, the evolution process of Mongolian traditional sports culture is the evolution process of Horqin traditional sports culture. Discussing the evolution process of Mongolian traditional sports culture is to let the relevant personnel understand the background of Mongolian traditional sports culture development and then 
promote the good development of Mongolian traditional sports culture [3].

\section{The Development Countermeasure of Horqin Mongolian Traditional Sports Culture}

In the 21st century, our government attaches great importance to the development of Horqin Mongolian traditional sports culture. The researchers also studied and discussed the traditional sports culture of Horqin Mongols, and then worked out a series of development strategies. The countermeasure itself should carry forward the traditional sports culture of Horqin Mongolian nationality on the basis of inheritance. The following will specifically discuss the development of Horqin Mongolian traditional sports culture to formulate countermeasures.

\subsection{Strengthening the Propaganda of Horqin Mongolian Traditional Sports Culture.}

At this stage, the Mongolian traditional sports culture, by the impact of modern sports culture, has not been better passed on and carried forward. Therefore, it is necessary to strengthen the propaganda of Horqin Mongolian traditional sports culture. For example, Horqin Mongolian traditional sports culture can gradually penetrate into the national fitness, which not only can enriches people's cultural life, but also inherits Horqin traditional sports culture. The main gathering place of Mongolian nationality is in Inner Mongolia Autonomous region, which, to a certain extent, makes the exchange between Mongolian nationalities more convenient, so the Mongolian nationality has unity in the tradition of inheritance and inheritance. Therefore, the increase of Horqin Mongolian traditional sports culture propaganda, can more effectively pass on and carry forward the traditional sports culture. In addition, encouraging Mongolians to participate in traditional sports, encouraging national fitness, can also increase the propaganda of Mongolian traditional sports culture. So far, many Mongolian activities have continued the tradition [4]. For example, Mongolian chess, although over time, slightly different names, but the method of playing chess from ancient times, is the same. Thus, Horqin Mongolian traditional sports culture is not submerged in the river of time. Encouraging Mongols to take part in traditional sports can not only make Mongolian people have strong physique, but also let Mongols feel the wisdom and courage of their ancestors, which is conducive to the cultivation of Mongolian people with strong character. Encouraging the national fitness can improve the national quality of Mongolian people and promote the penetration and inheritance of Horqin Mongolian traditional sports culture.

The innovation of Horqin Mongolian traditional sports culture should begin with the reform and innovation of Mongolian national sports. The reform innovation mainly manifests in the idea innovation and the way innovation. Idea innovation is to change the traditional cultural concept and make the Mongolian national sports idea more in line with the modern needs. The background of Horqin Mongolian traditional sports culture is mainly the place of hunting and killing and the place of war. Obviously, this is not in line with modern cultural ideas. Therefore, we should carry on the idea innovation, take the entertainment as the core idea, lets the people carry on the related Horqin Mongolian traditional sports item. For example, equestrian, wrestling, archery and so on, are mainly entertainment, supplemented by athletics, to carry out the project. Mode innovation, is to let Horqin Mongolian traditional sports culture in a new way to be passed down and carried forward. Zhang Xiaoping, born in Inner Mongolia, a Chinese boxer, won a gold medal in the $81 \mathrm{~kg}$ class at the 2008 Beijing Olympics. From this we can see that Mongolian sports as well as Mongolian athletes have greater room for growth and play [5]. Well, with regard to the inheritance of Horqin Mongolian traditional sports culture, we should allow Horqin Mongolian traditional sports not only to appear in Inner Mongolia Autonomous region, but also to have someone lead Horqin Mongolian traditional sports culture. Let Horqin Mongolian traditional sports culture go to the Asian Games, the Olympic Games or a broader stage, so that the world can understand the Horqin Mongolian traditional sports culture, can let Horqin Mongolian traditional sports culture carry forward.

\subsection{Strengthening the Training of Teachers.}

Mongolia is a minority, the level of economic and educational development is far less than Shanghai, Beijing and other cities. But education itself, carries on the dissemination and the 
development to the Horqin Mongolian traditional sports culture, has the unshirkable responsibility [6]. Therefore, our government should strengthen the training of traditional physical education teachers in Horqin Mongolia, which will not only speed up the spread of Horqin Mongolian traditional sports culture, but also improve the teaching level in Mongolia. Mongolian traditional physical education is different from traditional subject teaching. Traditional discipline teaching can introduce other excellent talents to improve education level. Mongolian traditional physical education, pay more attention to the combination of theory and practice, teachers are more demanding. As we all know, physical education should not only let students understand the relevant knowledge of physical education, but also give students a demonstration, so that students can master the key points of operation. As can be seen from this, Horqin Mongolian traditional physical education is more difficult. Therefore, the government should pay attention to strengthening the training of teachers.

\section{Conclusion}

Horqin Mongolian traditional sports culture is an important part of the diverse Mongolian culture. Related personnel, should attach importance to the further research and exploration of Horqin Mongolian traditional sports culture. In this paper, the evolution process of Horqin Mongolian traditional sports culture and the development countermeasures of Horqin Mongolian traditional sports culture are discussed in order to promote Horqin Mongolian traditional sports culture.

\section{Acknowledgement}

In this paper, the research was sponsored by Social Science Planning Project of Jilin Province Education Department during the 13th Five-Years Plan Period (Project No. [2016]17).

\section{References}

[1] Li Xinrong, Li Chunyan, Liu Zhongliang. Study on the Characteristics and Value of Mongolian Traditional Sports [J]. Neijiang Science and Technology, 2016(12).

[2] Tian Shuai, LIU Jiwu. Martial Arts Research on Mongolian Traditional Sports Culture [J]. Wushu Studies, 2017(11).

[3] Ba Zeda. Study on the Historical Development of the Mongolian Nadam Congress: A Case Study of East Wuzhimuqin Banner of Inner Mongolia [J]. Historical Records of Heilongjiang, 2015(12).

[4] Chu Lina. The Modern Reform of Mongolian Traditional Sports [J]. Journal of Zhengzhou University of Aeronautics (Social Science Edition), 2010(06).

[5] Bao Hugejiletu. Study on the Social Function of Mongolian Traditional Sports and the Origin and Evolution of the Mongolian Nadam [J]. Journal of Nanjing Sport Institute (Social Science), 2016(06).

[6] Ba Yaerjingele, BAO Dagula, BAO Hugejiletu. Study on the Origin and Evolution of Mongolian Traditional Sports [J]. Journal of Nanjing Sport Institute (Social Science), 2017(05). 